\title{
Knowledge, Attitude and Practice of Using ORS and Household Management of Childhood Diarrhoea
}

\author{
Acharya NC ${ }^{1}$, Dash DK², Mohanty MD³ , Agrawal P4, Dey P5
}

\section{Abstract}

Introduction: Diarrhoea is defined as the passage of three or more loose stools per day. Diarrhoea is one of the leading causes of childhood mortality in India. The objectives of the study were to assess household Knowledge, Attitude and Practice for prevention of Diarrhoea in children through preformed questionnaires. Material and Methods: Four hundred and sixty eight under five children were selected for study by Cluster sampling method. Background information, details of acute diarrhoea and treatment modalities were obtained from mother of the under five children. This was a hospital based study conducted at a tertiary care hospital, from $1^{\text {st }}$ May 2017 to $30^{\text {th }}$ December 2017. Results: About $70 \%$ of the moms were between the age assemble 25-32 years and the vast majority of them were housewives (72\%).A greater part $(>66 \%)$ of the moms were having essential/auxiliary education. Learning with respect to different parts of the diarrhoea and ORS surprisingly extremely unacceptable. In the present examination it is seen that learning in regards to ORS in looseness of the bowels is more in educated mother than uneducated. Three sitting of Educational mediations realized huge enhancement of the middle scores of learning, state of mind and practice expanded from 9, 6, 3 to 19, 14, 8, individually, Conclusion: The household knowledge regarding method of use and preparation of ORS for management of diarrhoea was observed to be lacking in this investigation. More estimates should be taken to enhance this learning and make moms mindful about the planning and utilization of ORS.

Key words: Diarrhoea, Intervention, Knowledge.

\section{Introduction}

$\mathrm{D}$ iarrhoea is still the second most vital enemy of kids all inclusive, with more than 800,000 under-fives kicking the bucket each year as indicated by UNICEF ${ }^{1}$. The primary purposes behind diarrhoeal assaults among youngsters are polluted water, un-healthiness, insufficient sanitation, poor cleanliness and absence of vaccination'. As per figures of the Health Ministry, in India, around 1.2 lakh youngsters younger than five capitulate to looseness of the bowels consistently ${ }^{1}$. This means 328 loose bowels passing consistently
${ }^{1}$ Dr. Naresh Chandra Acharya, MBBS, MD. Assistant Professor, ${ }^{2}$ Dr. Dillip Kumar Dash MBBS, MD, Professor, ${ }^{3} \mathrm{Dr}$. M.D. Mohanty MBBS, MD, Professor, ${ }^{4} \mathrm{Dr}$. Priyanka Agarwal, $2^{\text {nd }}$ year Post Graduate, ${ }^{5} \mathrm{Dr}$. Pratik Dey, $2^{\text {nd }}$ year Post Graduate. All from the Department of Paediatrics, IMS \& SUM Hospital, Bhubaneswar, Odissa, India.

\author{
Address for correspondence \\ Dr. Dillip Kumar Dash, Professor, \\ Department of Paediatrics, \\ IMS \& SUM Hospital, Kalinga Nagar, \\ Bhubaneswar, Odissa, India \\ Tel: +919437167337 \\ E-mail: drdillipdash10.10@gmail.com
}

\section{Acknowledgements: None \\ Funding: Nil \\ Conflict of Interest: None \\ Permission from IRB: Yes}

\section{How to cite}

Acharya NC, Dash DK, Mohanty MD, Agrawal P, Dey P. Knowledge, Attitude and Practice of Using ORS and Household Management of Childhood Diarrhoea. J Nepal Paediatr Soc 2018;38(2):94-101.

doi: http://dx.doi.org/10.3126/jnps.v38i2.19028

This work is licensed under a Creative Commons Attribution 3.0 License.

\section{(c) (i)}


per day and 13 consistently per hour. To be seen from 11-23 July, the Health Ministry propelled the across the nation 'Increased Diarrhoea Control Fortnight' (IDCF) under which different exercises have been arranged including visits by Accredited Social Health Activist (ASHA) specialists to every single such family unit which have kids younger than five. "ASHA specialists will visit all family units with kids beneath five years old for preparation and different aspect of ORS the ORS. They will clarify its advantages. The significance of this movement is that ORS will be accessible in the family unit when required at the season of looseness of the bowels. Also, all wellbeing offices will have ORS corners which will persistently exhibit the best approach to set up the ORS blend. Diarrhoea remains one of the leading global causes of death among children under the age of five years. ORS is simple, highly effective, inexpensive and appropriate therapy for diarrheal dehydration and since the introduction of ORT in 1979, there has been a steady decline in deaths due to diarrheal diseases ${ }^{11}$. Aim and objectives of this study were to assess household Knowledge, Attitude and Practice for prevention of Diarrhoea in Children through preformed questionnaires.

\section{Materials and Methods}

A cross-sectional descriptive study was carried out to assess the Knowledge, Attitude and Practice for household management of Diarrhoea in Children among mothers who attended the OPD at Institute of Medical Sciences and SUM Hospital Bhubaneswar over a period of eight months ( $1^{\text {st }}$ May to $30^{\text {th }}$ December 2017). A total of 468 mothers attended the paediatric OPD given their willingness to participate in the study. The mothers were enrolled in this study by using convenience sampling who had children of two months to five years of age. Children below two months, above five years and critically ill children needs ICU care were excluded from this study. In present study, data were collected by using a semi structured questionnaire. The knowledge and attitude of the mothers pertaining to ORS was defined as awareness about the availability and preparation of ORS and its use in the management of diarrheal diseases. The questionnaire included questions concerning the knowledge about childhood diarrhoea including its household management, role of ORS, method of preparation and also source of information about the household management of diarrheal diseases.

\section{Results}

In age insightful conveyance of mother under 25 year is $18.37 \%$ and 25 to multi year is $70 \%$ (Table 1 ).

Add up to 468 moms were met, just $24 \%$ were observed to work while remaining were housewives. In this investigation 54(11.53\%) mother having no formal training and $98(20.94 \%)$ no of mother were tertiary taught (Table-2).

Most extreme no of mother fall under secondary education class $(41.02 \%)$. In the current examination, the greater part of the respondents had a place with centre and lower financial category 209(44.65\%) and $157(33.54)$ respectively.102 $(21.79 \%)$ respondents had a place with the upper financial class (Table 3).

In these examination 276 moms utilizes boil water for drinking and just 134 utilizes water sanitizer as a wellspring of water. As a preventive part Proper waste transfer by 198 (42.30\%), hand washing 176(37.60\%) and utilization of sterile restroom is found in 296(63.24\%) cases (Table 4).

Table 1: Age wise Distribution of mother's Population in the study

\begin{tabular}{ccc}
\hline Age in Years & Mothers & $\mathbf{( \% )}$ \\
\hline $18-24$ & 86 & 18.37 \\
\hline $25-28$ & 172 & 36.75 \\
\hline $29-32$ & 156 & 33.33 \\
\hline 32 & 54 & 11.53 \\
\hline Total & 468 & 100 \\
\hline
\end{tabular}

Table 2: Educational status of mothers in the study

\begin{tabular}{ccc}
\hline Education Mother & Frequency & \% of Total \\
\hline No Formal & 54 & 11.53 \\
\hline Primary & 124 & 26.49 \\
\hline Secondary & 172 & 36.75 \\
\hline Tertiary & 118 & 25.21 \\
\hline Total & $\mathbf{4 6 8}$ & $\mathbf{1 0 0}$ \\
\hline
\end{tabular}

Table 3: Socio-economic status of mother's family

\begin{tabular}{ccc}
\hline Socio-economic status & Number & Percentage \\
\hline Upper & 102 & 21.79 \\
Middle & 209 & 44.65 \\
Lower & 157 & 33.54 \\
\hline
\end{tabular}

Table 4: Distribution of Mothers according to preventive measures has taken against diarrhoea.

\begin{tabular}{lcc}
\hline $\begin{array}{l}\text { Preventive measures } \\
\text { against diarrhoea }\end{array}$ & $\begin{array}{c}\text { No. of mothers } \\
(\mathbf{n = 4 6 8 )}\end{array}$ & Percentage \\
\hline $\begin{array}{l}\text { Using boiled water for } \\
\text { Drinking }\end{array}$ & 276 & 58.97 \\
\hline $\begin{array}{l}\text { Using water Sanitiser } \\
\text { for Drinking }\end{array}$ & 134 & 28.63 \\
\hline Proper hand washing & 176 & 37.60 \\
\hline Using sanitary latrine & 296 & 63.24 \\
\hline Proper waste disposal & 198 & 42.30 \\
\hline
\end{tabular}


In the present examination it is seen that learning in regards to ORS in looseness of the bowels is more in educated mother than uneducated gatherings. The consequences of training and learning are delineated in (Table 5 and 6) as pursues, No formal instruction $12(22.22 \%)$, tertiary $102(86.44 \%)$. Responses on the job of ORS were that it "diminishes water misfortune in looseness of the bowels," "decreases diarrheal frequency" and "renews water and electrolyte losses. Other different parts of ORS Knowledge i.e. correct preparation, Quantities of ORS, damage of giving excessively ORS and when to stop ORS is likewise better in well-educated mothers (Table 5 and 6 ).

As many as 103 (22\%) members knew how to plan ORS legitimately and could show the strategy for planning ORS (Table 5) Essential substitution treatment for the diarrhoea at home given by number of moms as pursues $186(39.74 \%)$ waters, sugar salt arrangement 192(41.02\%) and ORS 236(50.48\%). Other adjuvant liquid treatment given by the respondents are Pomegranate juice 78(16.66\%) and coconut water 122 (26.40\%) as shown in Table 7.

The dietary adjustment amid loose bowels is received by the investigation assemble moms as pursues, continued breast feeding 289 (61.75\%), reduced ordinary eating regimen 46 (9.82), increased standard eating routine 23 (4.91\%), greasy/slick nourishment $9(1.92 \%)$ and formula drain control is $189(40.38 \%)$ as in Table 7.

Basic learning in regards to cause, spread and counteractive action of the runs was extremely disappointing in our examination. Great learning in regards to cause, spread, and anticipation is $17.73 \%$, $16.23 \%$ and $16.66 \%$ separately just (Table 8 ).

Table 5: Correlation between mother's education and their knowledge regarding ORS

\begin{tabular}{|c|c|c|c|}
\hline Observations & Educational status of mothers & Number & Percentage \\
\hline \multirow{4}{*}{ Role of ORS } & No Formal (54) & 12 & 22.22 \\
\hline & Primary (124) & 36 & 29.03 \\
\hline & Secondary (172) & 97 & 56.39 \\
\hline & Tertiary (118) & 102 & 86.44 \\
\hline \multirow{4}{*}{ Preparation of ORS } & No Formal (54) & 8 & 14.81 \\
\hline & Primary (124) & 42 & 33.87 \\
\hline & Secondary (172) & 72 & 41.86 \\
\hline & Tertiary (118) & 84 & 71.18 \\
\hline \multirow{4}{*}{ Quantity of ORS } & No Formal (54) & 6 & 11.11 \\
\hline & Primary (124) & 39 & 31.45 \\
\hline & Secondary (172) & 104 & 60.46 \\
\hline & Tertiary (118) & 98 & 83.05 \\
\hline \multirow{4}{*}{$\begin{array}{l}\text { Harm of giving too } \\
\text { much ORS }\end{array}$} & No Formal (54) & 24 & 44.44 \\
\hline & Primary (124) & 72 & 58.06 \\
\hline & Secondary (172) & 109 & 63.37 \\
\hline & Tertiary (118) & 95 & 80.50 \\
\hline \multirow{4}{*}{$\begin{array}{l}\text { Danger of keeping ORS for a } \\
\text { longer period }\end{array}$} & No Formal (54) & 23 & 42.59 \\
\hline & Primary (124) & 76 & 61.29 \\
\hline & Secondary (172) & 117 & 68.02 \\
\hline & Tertiary (118) & 99 & 83.89 \\
\hline \multirow{4}{*}{$\begin{array}{l}\text { Stop ORS, if } \\
\text { vomiting continues }\end{array}$} & No Formal (54) & 7 & 12.96 \\
\hline & Primary (124) & 34 & 27.41 \\
\hline & Secondary (172) & 119 & 69.18 \\
\hline & Tertiary (118) & 101 & 85.59 \\
\hline \multirow{4}{*}{ When to stop ORS } & No Formal (54) & 3 & 5.55 \\
\hline & Primary (124) & 26 & 20.96 \\
\hline & Secondary (172) & 107 & 62.20 \\
\hline & Tertiary (118) & 93 & 78.81 \\
\hline
\end{tabular}


Table 6: Knowledge of mothers regarding different aspects of ORS

\begin{tabular}{|c|c|c|}
\hline Mothers' knowledge & Number & Percentage \\
\hline \multicolumn{3}{|l|}{ Role of ORS solution in diarrhoea: } \\
\hline Prevents dehydration & 119 & 25.42 \\
\hline Either increases or decreases diarrhoea & 193 & 41.23 \\
\hline No idea & 156 & 33.33 \\
\hline \multicolumn{3}{|c|}{ Steps for the preparation \& storage of ORS solution (out of 5 steps) } \\
\hline Did not mention any step & 102 & 21.79 \\
\hline One correct step & 221 & 47.22 \\
\hline Two or more correct steps & 145 & 30.98 \\
\hline \multicolumn{3}{|c|}{ Amount of ORS solution to be given for child below 2 years } \\
\hline Correct volume (50-100 ml) & 99 & 21.11 \\
\hline Incorrect volume & 312 & 66.66 \\
\hline Do not know & 57 & 12.17 \\
\hline \multicolumn{3}{|c|}{ Quantity of ORS solution to be given for child of 2 years or above } \\
\hline Correct volume (100-200 ml) & 89 & 19.01 \\
\hline Incorrect volume & 314 & 67.09 \\
\hline Do not know & 65 & 13.88 \\
\hline \multicolumn{3}{|l|}{ Harmful foods/fluids (out of 7 options): } \\
\hline One correct response & 168 & 35.89 \\
\hline Two correct responses & 127 & 27.13 \\
\hline Three correct responses & 106 & 22.64 \\
\hline Four correct responses & 67 & 14.31 \\
\hline \multicolumn{3}{|l|}{ Which diarrhoea is more dangerous: } \\
\hline Thin watery diarrhoea & 44 & 9.40 \\
\hline Red or green diarrhoea & 424 & 90.59 \\
\hline
\end{tabular}

Table 7: Distribution of respondents by Types of Fluid Given at Home, feeding pattern and restricted foods

\begin{tabular}{lcc}
\hline Observations & Number & Percentage \\
\hline Water & 186 & 39.74 \\
\hline Sugar salt solution (SSS) & 192 & 41.02 \\
\hline $\begin{array}{l}\text { Oral rehydration solution } \\
\text { (ORS) }\end{array}$ & 236 & 50.48 \\
\hline Pomegranate juice & 78 & 16.66 \\
\hline Coconut water & 122 & 26.40 \\
\hline Continue breast feeding & 289 & 61.75 \\
\hline Reduce regular diet & 46 & 9.82 \\
\hline Increase regular diet & 23 & 4.91 \\
\hline Greasy/oily food & 9 & 1.92 \\
\hline Formula milk powder feed & 189 & 40.38 \\
\hline Only solid food & 29 & 6.19 \\
\hline Only liquid food & 67 & 15.31 \\
\hline Others & 92 & 19.65 \\
\hline
\end{tabular}

Table 8: Knowledge about cause, spread and prevention of diarrhoea of the respondents

\begin{tabular}{lcc}
\hline $\begin{array}{l}\text { Distribution of respondents } \\
\text { by knowledge }\end{array}$ & Number & Percentage \\
\hline Cause & 83 & 17.73 \\
\hline Good & 286 & 61.11 \\
\hline Average & 99 & 21.15 \\
\hline Poor & & \\
\hline Spread & 76 & 16.23 \\
\hline Good & 223 & 47.64 \\
\hline Average & 169 & 36.11 \\
\hline Poor & & \\
\hline Prevention & 78 & 16.66 \\
\hline Good & 199 & 42.52 \\
\hline Average & 191 & 40.81 \\
\hline Poor & 98 & 20.9 \\
\hline Home management of diarrheal disease & \\
\hline Good & 192 & 41.02 \\
\hline Average & 178 & 38.03 \\
\hline Poor & &
\end{tabular}


Drugs used for diarrhoea, as indicated by parents of children treated at different peripheral health centre

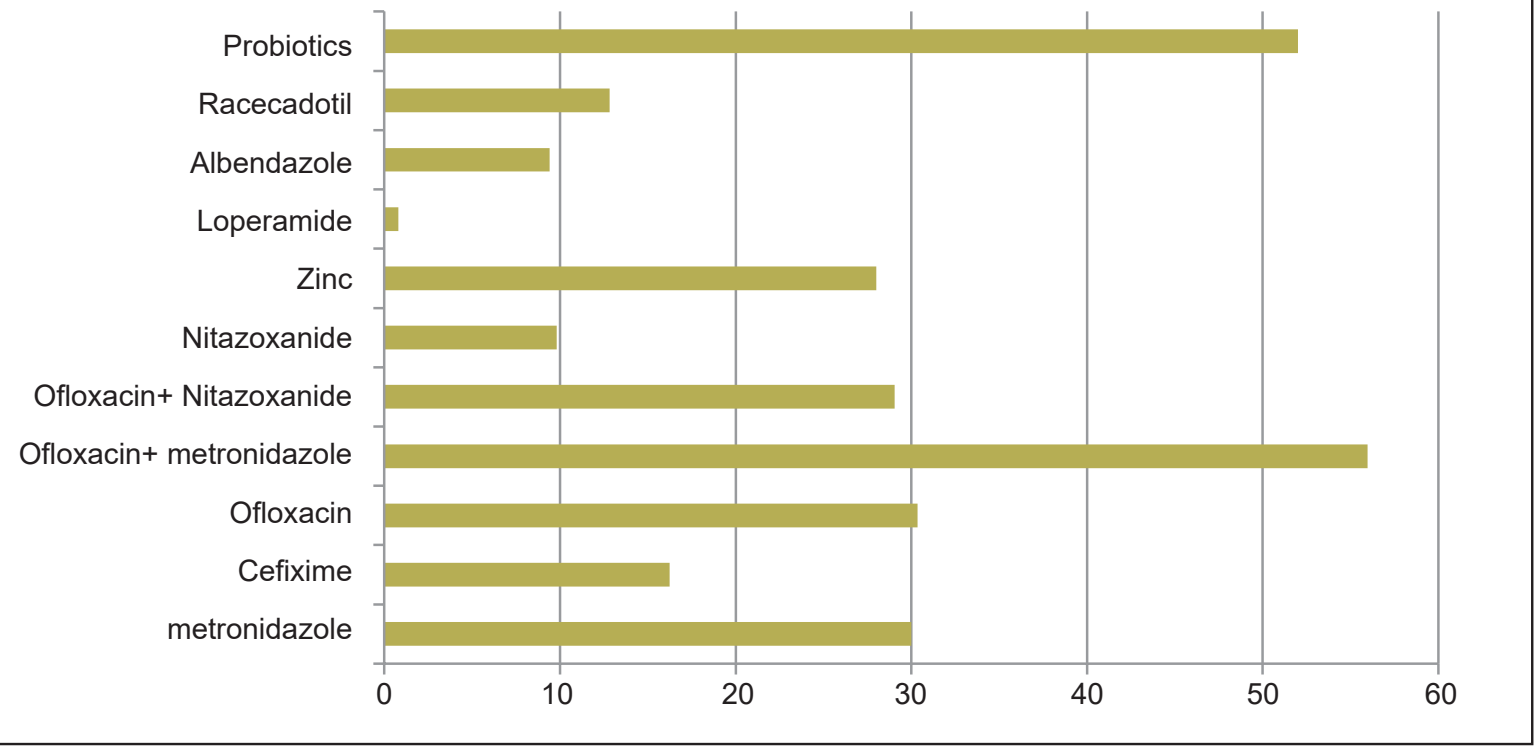

Fig 1: Showing drugs used for treatment of diarrhoea

First choice of intervention by parents during a child's diarrhoeal episode

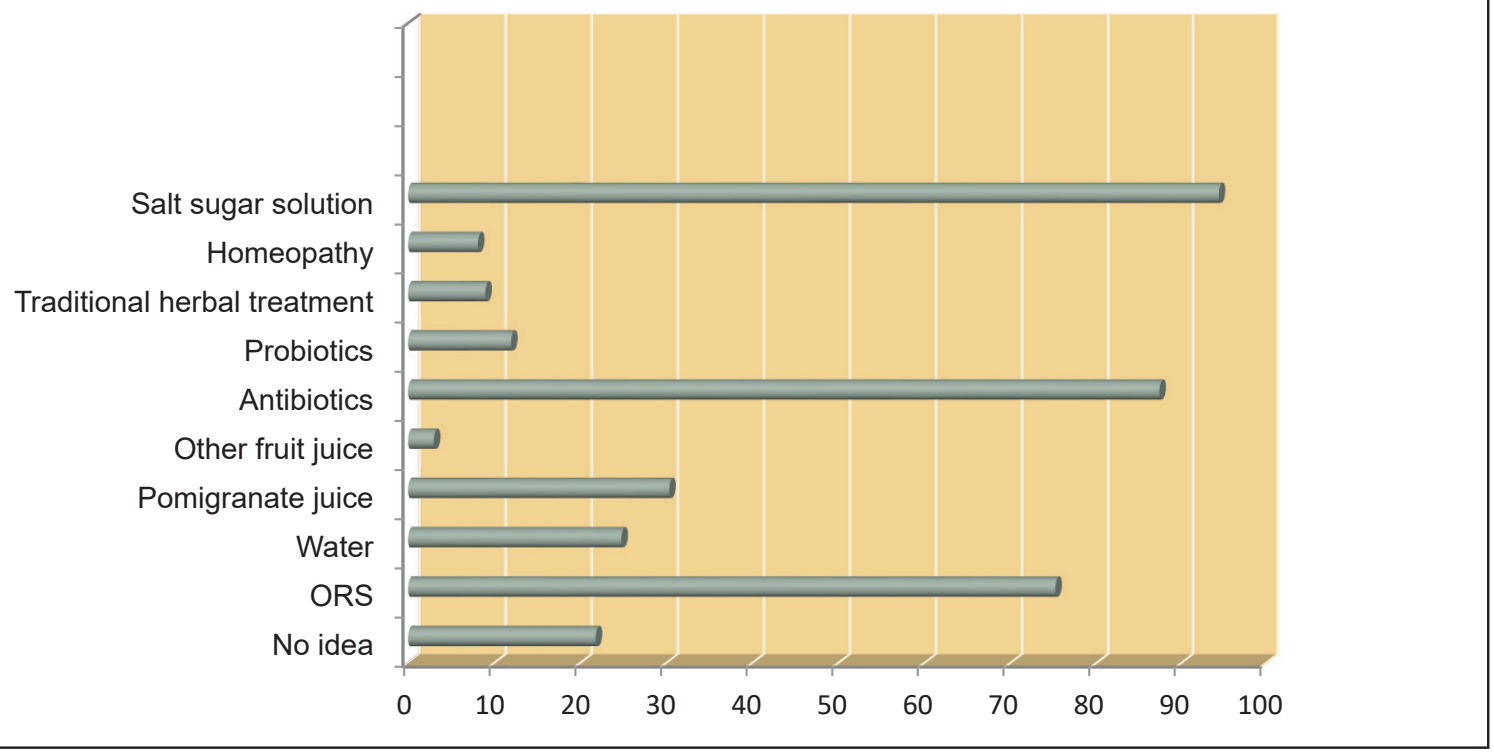

Fig 2: First choice of intervention by parents during a child's diarrhoeal episode

Of the aggregate members, 147 (31.41\%) had learning in regards to hand crafted ORS; generally utilized natively constructed ORS by members were kanji, sugar and salt arrangement, buttermilk with salt and daal ka pani (lentil soup). Reactions of the investigation members to the survey with respect to treatment are outlined in Figure 1. Maximum number of mothers utilizes probiotics $64 \%$, Ofloxacin + metronidazole $57 \%$ and Zinc 61\%. Another vital perception in our examination in regards to first choices mediation to be taken amid looseness of the bowels is Sugar Salt Solution $88 \%$, Antibiotics $84 \%$, ORS 70\% and just water $22 \%$ (Figure 2).

\section{Discussion}

Diarrhoea stays one of the main worldwide reasons for death among youngsters younger than five years. ORS is straightforward, exceedingly compelling, economical and suitable treatment for diarrheal drying out and since the presentation of ORT in 1979, there has been an unfaltering decrease in passing because of diarrheal ailments ${ }^{1}$. Diarrhoea is the frequent (typically characterized as at least three times in multi day) passage of liquid or soft stool ${ }^{2,3}$ It is the most widely recognized clinical indication of gastrointestinal infection and the second driving reason for death on the planet 
among kids under five years old ${ }^{3,4,5}$. Unfortunately, particularly in developing nations, because of absence of legitimate information in mother, with respect to accessibility, planning and utilization of ORS, this objective is a long way from accomplished. Improper sterile conditions, risky drinking water and absence of cleanliness are likewise in charge of not ready to diminish the occurrence of diarrhoeal ailments. The outcomes are fairly unique in relation to the investigation completed by Sultana A. et al. in Rawalpindi who discovered that $60 \%$ mothers were found to have satisfactory learning in regards to the strategy for ORS readiness though a similar data was seen to be fractional and deficient among $35.94 \%$ and $4.06 \%$ respondents albeit $61.87 \%$ moms were having a place from centre social class ${ }^{56}$.It was found in an instructive intercession contemplate in Nepal by Mukhtar Ansari et al that Education realized huge enhancement in information, state of mind and practice at first, second and third development. The middle scores of information, disposition and practice expanded from $14,7,6$ to $26,9,13$, individually, because of rehashed intercessions. Besides, intercessions reinforced the connection between information, mentality and practice ${ }^{67}$. Study directed by Rasania et al. ${ }^{78}$ have detailed that $69.8 \%$ of the members knew with respect to the job of ORS in looseness of the bowels and just $38.7 \%$ knew how to plan ORS legitimately. Dhadave et al. ${ }^{89}$ have detailed that $65.7 \%$ of the members thought about ORS, and the mindfulness was more in literates when contrasted with uneducated people. Cantered wellbeing instruction of moms has been appeared to enhance their insight and practice in the utilization of ORS in the diarrhoea ${ }^{9,10}$. According to NFHS, in India $43 \%$ of ladies thought about ORS pockets yet just $26 \%$ at any point utilized it ${ }^{910}$.Similar results were obtained in the study by Widarsa KT et al. ${ }^{10,11}$ Though a large portion of the ladies knew about the ORS powder, just third of them knew the correct method for utilizing it. This extent is comparative when contrasted with the information accessible from NFHS III in which it is $30 \%{ }^{11,12}$. Knowledge in regards to the preventive measures is likewise insufficient among the moms. Over $60 \%$ of them couldn't recognize even a solitary measure from the choices gave to them. To strengthen the prior articulation, centred wellbeing training of moms in such manner might be of helpful $9,10,12,13$. In our examination, about $45 \%$ of the moms were of the misguided judgment that getting teeth is the explanation behind advancement of the runs. The greatness of this misguided judgment is likewise archived in different examinations directed in India and in addition Iran, in these investigations the size is $64 \%$ and $48 \%$ respectively ${ }^{13,14,15}$. A not very many moms had information in regards to the reason for looseness of the bowels. Just $17 \%$ of them gave rectify answer i.e. disease as the reason for the runs. Cabatbat, et al in their examination led in Philippines reports $77 \%, 34 \%$ and $23 \%$ moms recognizing dangerous drinking water, inability to wash hands in the wake of pooping, and subsequent to taking care of loose motion separately as regular purposes behind diarrhoeal diseases ${ }^{14,15,16}$. Knowledge with respect to the eating regimen to be pursued amid a scene of loose bowels is likewise restricted among the moms. Almost $40 \%$ of the members said that eating routine should be limited amid the assault of looseness of the bowels. These perceptions are steady with the perceptions made in research directed by Suman, et al in Puducherry ${ }^{16,17}$. In an investigation directed in south east area of Iran, Khalili, et al announced $81 \%$ and $58 \%$ moms recognizing risky water and unclean hands individually as reasons for diarrhoeal illness ${ }^{17,18}$. For children on normal family diet, regular solid food and fluid intake was increased by $(13.9 \%$ and $18.4 \%)$ and $(7.6 \%$ and $16.5 \%)$ of the care-givers respectively. Continuous breastfeeding was practiced by all mothers $(100 \%)$ while continued feeding with solid food and increased fluid was given in $81.00 \%$ and $61.30 \%$ respectively, in Yala community (Okoro, 2000).Different parts of network administration of youth diarrheal ailment, of specific concern are dietary limitations, utilization of anti-infection agents and acknowledgment of threat signs that require looking for expert help outside home (McLennan, 2002) ${ }^{17,18}$. About $(11.1 \%$ and $22.7 \%)$ and $(28.5 \%$ and $40.3 \%)$ of the contemplated guardians, each confined greasy/ slick sustenance and powdered drain separately. In the meantime around $15.4 \%$ and $9.3 \%$ of them confined equation feed to their children ${ }^{17,18}$. Though moms knew about a few signs of dehydration, the level of learning about the real indications of lack of hydration because of looseness of the bowels was exceptionally poor. The examination directed in Tanzania and Indonesia likewise found comparative results ${ }^{18,1919,20}$. Sustaining ought to be proceeded except if generally minimal particular condition needs dietary change. In this study $63 \%$ were having good knowledge on sanitary latrine uses in relation to goo preventive measure of diarrhoea. About the proper source of drinking water $63 \%$ mothers had good knowledge and rest $26 \%$ and $11 \%$ were having average and poor knowledge respectively. Regarding preparation of ORS $30.98 \%$ mothers had good knowledge, $47.22 \%$ mothers had average knowledge and rest $21.79 \%$ had poor knowledge as depicted above. Similarly, as mentioned above $30.98 \%$ mothers were able to mention all the steps for the correct and complete preparation of ORS solution which is Similar to the other studies which found approximately $20 \%$ to $50 \%$ of the mothers were able to prepare ORS solution correctly and completely ${ }^{20,21,22,23}$. This may be because 
of moms' absence of related knowledge, an absence of legitimate training about the concerned issues and their ethnicity itself ${ }^{23,24}$. With respect to utilization of ORS, maximum moms were inadequate with regards to learning of giving the right sum (67\%). Conversely, the utilization of anti-infection agents, antifungals, anthelminthic and antidiarrheal drugs is across the board in diarrhoea ${ }^{24,25,26,27}$ which is very like our present study $(67 \%)$. The significance of breastfeeding amid loose bowels has been sufficiently highlighted by Zwisler $\mathrm{G}$ et $\mathrm{al}^{26,27}$. A examine by Christopher $\mathrm{S}$ Yilgwan et al on predominance of the runs sickness and hazard factors indicated coordinate connection of pervasiveness of looseness of the bowels with low training and low financial status of mothers ${ }^{27,28}$. It is necessary to strengthen parents' knowledge about diarrhoea and its

\section{References}

1. Victora CG, Bryce J, Fontaine O, Monasch R. Reducing deaths from diarrhoea through oral rehydration therapy. Bull World Health Org 2000;78(10):1246-55

2. IDCF 2017 Intensified Diarrhoea Control Fortnight 12-24 June 2017, OPERATIONAL GUIDELINES Ministry of Health \& Family Welfare, Government of India, http://www.huffingtonpost.in/2016/07/11/13children-die-of-diarrhoea-every-hour-in-india-healthministr_a_21430279/.

3. Bühler HF, Ignotti E, Neves SM, HaconSde S. Spatial analysis of integrated health and environmental indicators for morbidity and mortality due to infant diarrhea in Brazil, 2010. Cad Saude Publica 2014;30(9):1921-934. DOI:10.1590/0102311X00218717

4. Mandomando IM, Macete EV, Ruiz J, Sanz S, Abacassamo $F$, Valles $X$, et al. Etiology of diarrhoea in children younger than 5 years of age admitted in a rural hospital Southern Mozambique. Ame J Trop Med Hyg 2007;76:522-27. DOI: 10.4269/ajtmh.18-0537

5. Jegede EF, Oyeyi ET, Bichi AH, Mbah HA, Torpey K. Prevalence of intestinal parasites among HIVIAIDS patients attending Infectious Disease Hospital Kano, Nigeria. Pan Afr Med J 2014;17:295. DOI: 10.11604/ pamj.2016.23.47.8934

6. Ibrahim MM, Aden AS, Omar HM, Wall S, Persson LA. Diarrhea among children in rural Somalia. Maternal perceptions, management and mortality. Ann Trop Paediatr 1994;14(3):215-22. DOI: 10.1179/14653281 11Y.0000000009.

7. Ahmed A, Malik IA, Iqubal $M$ et al. The use of ORS (NIMKOL) in management of childhood diarrhoea by mothers in the suburbs of Rawalpindi, Islamabad. $J$ Pak Med Asso 1990;8:178-82. DOI: 10.1186/14712407-10-594 treatment during hospital consultations, but also during health campaigns and through the media ${ }^{27,28 .}$

\section{Conclusion}

It is very sensible to presume that the learning with respect to the planning and utilization of ORT by guardians in eastern Odisha region is inadequate. This investigation uncovers uncontrolled utilization of superfluous prescription i.e. anti-infection agents, probiotics and numerous all the more separated from the imperative ones like zinc and ORS. Preparation of Sugar Salt Solution and ORS should be demonstrated properly at health centres as a small group. Proper use of ORS in a diarrhoeal episode along with early recognition of dehydration and continuation of breastfeeding with other dietary treatment should be focused upon.

8. Rasania SK, Singh D, Pathi S, Matta S, Singh S. Knowledge and attitude of mothers about oral rehydration solution in few urban slum of Delhi. Health Popul Perspect Issues 2005;28(2):100-07.

9. Dhadave MM, Kumar A, Reddy S, Vijayanath V. A study on diarrhea related practices awareness of ORS among mothers of under-five children attending OPD, CHTC, Rajpur. J Pharm Biomed Sci 2012;19(19):1-3. DOI: doi/ pone.0002744. 3.

10. Pahwa S, Kumar GT, Toteja GS. Performance of a community-based health and nutrition-education intervention in the management of diarrhoea in a slum of Delhi, India. J Health Popul Nutr 2010;28:553-9. DOI: 10.1186/s41043-018-0141-5.

11. Widarsa KT, Muninjaya AA; Factors associated with the use of oral rehydration solution among mothers in west Lombok, Indonesia; J Diarrhoeal Dis Res 1994:12(4):261-64. DOI: https://doi. org/10.1177/014107688407700424

12. National Family and Health Survey, India. NFHS3 (2005-2006). Available at:http://rchiips.org/nfhs/ NFHS-3\%20Data/VOL-1/Chapter\%2009\%20- \%20 Child\%20Health\% 20(562K).pdf. Accessed on March 1, 2016.

13. Rishi RK, Bodakhe SH, Tailang M. Patterns of use of oral rehydration therapy in Srinagar (Garhwal), Uttaranchal, India. Trop Doct 2003;33:143-5. DOI: 10.1177/0049475518804696.

14. Kapoor P, Rajput VJ. Maternal knowledge, attitudes and practices in diarrhoea. Indian Pediatr 1993;30:857.

15. Khalili M, Mirshahi M, Zarghami A, Rajabnia MC, Farahmand F. Maternal knowledge and practice regarding childhood diarrhoea and diet in Zahedan, Iran. Health Scope 2013;2(1):19-24. DOI: 10.5812/ jhs.7253. 
16. Cabatbat AM. The effect of health education on the knowledge, attitudes and practices (KAP) on the mothers on diarrhoea in Barangay, Paglaun, Dumalinao, Zamboanga Del Sur. Zamboanga Medical School Foundation. 1999. Available at: http://som. adzu.edu.ph/research/pdf/2008-05-09- 100350 cabatbat.pdf. [Cited on 2013, August 16].

17. Saurabh S, Shidam UG, Sinnakirouchenan M, Subair M, Hou LG, Roy G. Knowledge and Practice Regarding Oral Rehydration Therapy for Acute Diarrhoea among Mothers of Under-Five Children in an Urban Area of Puducherry, India. Natl J Community Med 2014;5(1):100-4. DOI:10.4103/0970-258X.243404

18. McLennan JD (2002). Home Management of Childhood Diarrhoea in a Poor Periurban Community in Dominican Republic. J Health Popul Nutr 2002;20(3):245-254 DOI: http://dx.doi.org/10.3329/jhpn.v31i3.16832

19. MacDonald SE, Moralejo DG, Mathews MK. Maternal understanding of diarrhoea-related dehydration and its influence on ORS use in Indonesia. Asia Pac J Public Health 2007;19(1):34-9. DOI: 10.1177/1010539512462507

20. Kaatano GM, Muro Al, Medard M. Caretaker's perceptions, attitudes and practices regarding childhood febrile illness and diarrhoeal diseases among riparian communities of Lake Victoria, Tanzania. Tanzan Health Res Bull 2006;8(3):155-61. DOI: http://dx.doi.org/10.4314/thrb.v14i3

21. Jha N, Singh R, Baral D. Knowledge, attitude and practices of mothers regarding home management of acute diarrhoea in Sunsari, Nepal. Nepal Med Coll J 2006;8(1):27-30. DOI: 10.1258/ebm.2012.012014

22. MacDonald SE, Moralejo DG, Matthews MK. Correct preparation and administration of oral rehydration solution: essential for safe and effective home treatment of diarrhea in Indonesia. Int Q Community Health Educ 2005;24(3):205-14. DOI: 10.2190/IQ.29.1.a

23. Rehan HS, Gautam K, Gurung K. Mothers needs to know more regarding management of childhood acute diarrhea. Indian J PrevSoc Med 2003;34(1\&2):40-5.

24. Levine AC, Munyaneza RM, Glavis-Bloom J, Redditt V, Cockrell HC, Kalimba B, Kabemba V, Musavuli J, Gakwerere M, Umurungi JP, Shah SP, Drobac PC. Prediction of severe disease in children with diarrhea in a resource-limited setting. PLoS One 2013;8(12). DOI:10.1371/journal.pbio.0040401.

25. Sood N, Wagner Z. Private sector provision of oral rehydration therapy for child diarrhea in sub-Saharan Africa. Am J Trop Med Hyg 2014;90(5):939-44. DOI: https://doi.org/10.4269/ajtmh.18-0203. [PMC free article] [PubMed]

26. Baqui AH, Black RE, El Arifeen S, Yunus M, Zaman K, Begum N, et al. Zinc therapy for diarrhoea increased the use of oral rehydration therapy and reduced the use of antibiotics in Bangladeshi children. $\mathrm{J}$ Health Pop Nutr 2004;22(4):440-42. DOI: 10.3329/jhpn. v29i1.7567.

27. Zwisler G, Simpson E, Moodley M. treatment of diarrhea in young children: results from surveys on the perception and use of oral rehydration solutions, antibiotics, and other therapies in India and Kenya. Journal of Global Health. 2013;3(1):1-14. DOI: 10.4172/2161-1165.1000e121.

28. Yilgwan CS, Okolo SN. Prevalence of diarrhea disease and risk factors in Jos University Teaching Hospital, Nigeria. Annal African Med 2012:11(4):217-21. http:// dx.doi.org/10.4103/1596-3519.149912 